\title{
Decolonizing Description: First Steps to Cataloguing with Indigenous Syllabics
}

\author{
Luc Fagnan ${ }^{1}$
}

${ }^{1}$ School of Library and Information Studies, University of Alberta, Email: Itfagnan@ualberta.ca

To Cite:

Fagnan, L. (2020). Decolonizing description: First steps to cataloguing with Indigenous syllabics. [Special Issue]. Pathfinder: A Canadian Journal for Information Science Students and Early Career Professionals, 1(1), 33-40. https://doi.org/10.29173/pathfinder21

\begin{abstract}
In light of the TRC Calls to Action from 2015 and the CFLA's Truth \& Reconciliation Report and Recommendations from 2017, many libraries in what is known as Canada have begun to take steps towards decolonization. Decolonizing bibliographic descriptions in library catalogues is an important part of this process, as this can impact both the ability to access Indigenous materials and the representation of Indigenous Peoples and Knowledges in the library.

While various efforts to work towards accurately and respectfully representing Indigenous Peoples and Knowledges in library catalogues are ongoing, the inclusion of Indigenous Syllabics in bibliographic records is one way in which cataloguers can begin to put these efforts into action. In addition to collaborating with Indigenous community members and Indigenous librarians on this work, there are a variety of resources and tools available online that can aid cataloguers in creating accurate and culturally appropriate descriptions of Indigenous materials. This extended abstract provides context and information that is central to this work, and gives a cursory overview of how one might insert Indigenous Syllabics into bibliographic records.
\end{abstract}

Keywords: Syllabics, Decolonization, Indigenous Syllabics, Cataloguing, Cree, Inuktitut

$n$ recent years, efforts to revitalize and bring awareness to Indigenous languages have continued to grow. Particularly in what is known as Canada, the Truth and Reconciliation Commission's (TRC) Calls to Action and the ensuing Canadian Federation of Library Association's (CFLA) Report and Recommendations have encouraged libraries to adopt more respectful practices regarding Indigenous Knowledges, languages, and cultures (Truth and Reconciliation Commission, 2015;

Pathfinder: A Canadian Journal for Information Science Students and Early Career Professionals, 1(1), 33-40. ISSN 2563-2493 
Canadian Federation of Library Associations, 2017). For settler librarians, this emphasis on Indigenous representation in libraries highlights the demands for decolonizing their work and brings opportunities to decolonize the very institutions at which they are employed.

As a settler of European descent, the author of this paper respectfully acknowledges that his work on this topic is taking place on Treaty 6 Land and in Métis Region 4, and he recognizes that he still has much to learn about Indigenous Ways of Knowing. As a student employee at the University of Alberta Library, the author has taken on this work in an effort to ensure that it is transformative rather than performative, to learn from any mistakes made along the way, and to challenge assumptions that are often made in cataloguing processes.

Many libraries have responded to the TRC's Calls to Action and the CFLA's recommendations by decolonizing spaces, collections, or services (Robinson, 2019), yet there is much work that remains to be done to decolonize descriptions in bibliographic records created for Indigenous materials. Working towards reconciliation in libraries, preserving the connection between Indigenous languages and cultures, and accurately representing Indigenous Knowledges in a culturally appropriate manner are all crucial factors in this process.

\section{Reconciliation In Libraries}

To better understand why this work is important and how it can be beneficial to Indigenous Peoples, we must consider how it contributes to reconciliatory efforts in libraries. As Desmond Wong states about decolonizing public libraries, many librarians want to contribute to these efforts but often feel paralyzed or overwhelmed by the work involved (Robinson, 2019). However, Wong affirms that this non-action is damaging because it perpetuates harm to Indigenous library users and continues to maintain the settler-colonial oppression of Indigenous Peoples (Robinson, 2019; Blair \& Wong, 2018).

In response to the TRC's Calls to Action and the CFLA's ensuing Report and Recommendations, the University of Alberta Library created a Decolonizing Description Working Group. The purpose of the group was to create a "[...] plan of action for how descriptive metadata practices could more accurately, appropriately, and respectfully 
represent Indigenous [P]eoples and contexts" (Farnel et al., 2018, p. 12). While the current status of this plan is not known, this kind of work will require a long period of time to properly put into action (Farnel et al., 2018, p. 21).

However, there is at least one way in which bibliographic records can be decolonized relatively quickly and it does not require the authorization of governing bodies or major systemic changes in the cataloguing world. By inserting Indigenous Syllabics into records, cataloguers can create a more accurate representation of Indigenous Knowledges and their associated contributors in library catalogues.

\section{Language \& Culture}

In preparing to catalogue with Indigenous Syllabics, the author of this paper set out to challenge the assumption that Indigenous Peoples want to have their languages represented in bibliographic records and library catalogues. Making assumptions about what is beneficial to Indigenous Peoples may lead to culturally inappropriate representations and can continue to perpetuate colonial harms. Whenever possible, creating opportunities for collaboration with Indigenous community members can ensure that decolonization work is meaningful and beneficial. With the intent to represent Indigenous languages more accurately in the University of Alberta Library's catalogue, it was important to consider whether this work would be beneficial to Indigenous Peoples.

Métis writer and educator Chelsea Vowel, also known as âpihtawikosisân, states in a blog post that "language cannot be taught in a vacuum" (Vowel, 2011, para. 15) and expresses that it is incredibly empowering to see Indigenous languages being taken seriously. Teneya Gwin, a Cree Métis woman working as the Indigenous service design lead for the Calgary Public Library, learned from Elders in communities on Treaty 7 Land that language was the number one thing that would make libraries more welcoming to them. On this, she says "[t]o revitalize a culture you need that connection to language" (Robinson, 2019, para. 25). This perspective implies that the representation of Indigenous languages in libraries can contribute to the preservation and revitalisation of Indigenous cultures. Additionally, Vowel (2011) believes both Indigenous and non-Indigenous students lack information about Indigenous history and culture and argues that one cannot "effectively engage in this kind of historical and 
cultural learning without at least some language learning" (para. 17). Representing Indigenous languages in library catalogues is therefore a crucial step towards creating opportunities for all to learn about Indigenous cultures, which may have historically been inaccessible.

With this notion in mind, how can non-Indigenous academics and librarians contribute to this work? In speaking with Métis colleagues and continuing to research these topics, the author has come to believe that librarians can do their part by building capacity for such work to continue. By taking down restrictions and barriers, by building bridges but not forcing people to cross them or taking credit for it, and by being an ally while respecting boundaries, decolonization can create opportunities for work like language revitalization, which lies in the realm of Indigenization and Indigenous Resurgence (Betasamosake Simpson, 2016).

\section{Origins of Indigenous Syllabics}

We must also try to understand where Indigenous Syllabics come from in order to carry out this work respectfully and culturally appropriately. According to the Lexico online dictionary powered by Oxford, a syllabic can be defined as a written character that represents a syllable (Lexico, n.d.). A concept equally integral to this work is transliteration, which refers to the method of mapping from one system of writing to another based on phonetic similarity (Google, n.d.). It is worth noting that a "transliteration" is different from a "translation", as the conversion is based on the pronunciation rather than the meaning.

It is equally important to know that some Indigenous Peoples believe Syllabics are a colonizer invention, while others believe they were a gift from the Creator unrelated to the arrival of settlers (Rigby, 2015; Cree Literacy Network, n.d.; Stevenson, 1999). The name often associated with origin stories of Cree Syllabics is James Evans, a Methodist missionary (Stevenson, 1999). Some claim he invented Syllabics, while others claim that he simply popularized them (Cree Literacy Network, n.d.). However, the belief that Inuktitut Syllabics were later adapted from Cree Syllabics is a belief that appears to be widely shared and accepted (Rigby, 2015). Regardless, we must ensure that Indigenous languages are treated as their own distinct languages with their own distinct dialects and histories, and thus avoid employing pan-Indigenous perspectives 
whenever possible. Using pan-Indigenous terms when referring to particular communities can promote the misconception that all Indigenous Peoples have one shared identity and culture, thereby promoting the erasure of their distinct cultures and histories. In any case, the multitude of different perspectives at play demonstrates that many voices are present in this conversation and they must be included and welcomed in the process of this work.

\section{Cataloguing with Indigenous Syllabics}

Keeping in mind the connection between Indigenous languages and cultures, we must also have knowledge of cataloguing standards to consider when cataloguing with Indigenous Syllabics. For example, the Library of Congress Program for Cooperative Cataloging (PCC) has guidelines for creating records in multiple characters sets, and Resource Description and Access (RDA) stipulates that information should be recorded as it appears on the resource (Library of Congress, 2017; RDA Toolkit, n.d.). While many vendors will provide ready-made bibliographic records in dozens of languages in order to adhere to these standards, there do not appear to be any companies that provide records containing any Indigenous Syllabics. For this reason, cataloguers must be prepared to respectfully and accurately represent the Indigenous languages spoken on the Land where they work and beyond.

To be able to catalogue with Indigenous Syllabics, one must ensure they have the appropriate fonts and keyboards installed. The font Aboriginal Sans Serif and the Cree keyboard layout available from LanguageGeek are both commonly cited and recommended in online blogs (Ogg, 2017; LanguageGeek, n.d.). Inuktitut keyboard layouts are currently available in both Microsoft Windows and Mac OS language settings. Keyboard maps can be found linked from their respective LanguageGeek webpages and an Inuktitut keyboard map can be found on the Government of Nunavut's website (Government of Nunavut, n.d.). Once cataloguers have installed the appropriate fonts and keyboard layouts of the Indigenous languages they wish to catalogue with and have familiarized themselves with the process of typing, they can begin inserting Indigenous Syllabics into bibliographic records. The ability to create parallel MARC fields in records on platforms such as OCLC's Record Manager is quite 
convenient in this work. Without this ability, a separate 880 MARC field would have to be created for each field in which Syllabics are to be inserted. This results in several 880 MARC fields present in the record to represent common MARC fields such as the $100,245,264$, or 700 fields, acting as surrogates of each respective field. These 800 MARC fields are the fields in which Syllabics can be inserted. The author encourages cataloguers to consider inserting Indigenous Syllabics into Master Records on shared platforms such as OCLC's WorldCat, as the records can then be copy-catalogued by other institutions and would increase the representation of Indigenous languages beyond a single library's catalogue.

\section{Future Steps}

In conclusion, there is much work left to be done to ensure that Indigenous Peoples and Knowledges are appropriately represented in library catalogues. A key component of this process that cannot be overlooked is relationship building and community collaboration with Indigenous Peoples. Long term or permanent librarian roles should be created to ensure the longevity of this work in libraries and beyond, and Indigenous librarians should be given priority when seeking candidates to catalogue in Indigenous languages. These efforts should be ongoing throughout every stage of implementation for cataloguing with Indigenous Syllabics. Non-Indigenous librarians cannot continue to make assumptions about the ways in which Indigenous Peoples are represented in library catalogues, and they must be prepared to engage in culturally appropriate cataloguing.

\section{References}

Betasamosake Simpson, L. (2016). Indigenous Resurgence and Co-resistance. Critical Ethnic Studies, 2(2), 19-34. https://doi.org/10.5749/jcritethnstud.2.2.0019 Blair, J., \& Wong, D. (2018). Moving in the Circle: Indigenous Solidarity for Canadian Libraries. Partnership: The Canadian Journal of Library and Information Practice and Research, 12(2), 1-7. https://doi.org/10.21083/partnership.v12i2.3781 Canadian Federation of Library Associations. (2017). Truth and Reconciliation Report and Recommendations. http://cfla-fcab.ca/wp-content/uploads/2018/10/Truthand-Reconciliation-Committee-Report-and-Recommendations-ISBN1.pdf 
Cree Literacy Network. (n.d.). Another version of Cree Literacy: The Cree story of Syllabics. Retrieved February 2, 2020, from https://creeliteracy.org/beginning-toread-plains-cree-in-standard-roman-orthography/another-version-of-cree-literacythe-cree-story-of-syllabics/

Farnel, S., Koufogiannakis, D., Laroque, S., Bigelow, I., Carr-Wiggin, A., Feisst, D., LarSon, K. (2018c). Rethinking Representation: Indigenous Peoples and Contexts at the University of Alberta Libraries. The International Journal of Information, Diversity, \& Inclusion, 2(3), p. 9-25. https://doi.org/10.7939/R37H1F309

Google. (n.d.). Transliteration. Google Input Tools. Retrieved February 5, 2020, from https://www.google.com/inputtools/services/features/transliteration.html Government of Nunavut. (n.d.). Computer Tools. Retrieved February 1, 2020, from https://www.gov.nu.ca/culture-and-heritage/information/computer-tools

LanguageGeek. (n.d.). Algonquian Syllabics Keyboard Layout. http://www.languagegeek.com/syllabicskb/algonquiansyllabics.html

Lexico. (n.d.). Meaning of syllabic in English. Retrieved February 6, 2020 from https://www.lexico.com/definition/syllabic

Library of Congress. (2017). PCC Guidelines for Creating Bibliographic Records in Multiple Character Sets. Retrieved January 25, 2020 from https://www.loc.gov/aba/pcc/bibco/documents/PCCNonLatinGuidelines.pdf Ogg, Arden. (2017, November 10). Typing Syllabics on your Computer: Installing what you need via LanguageGeek. Cree Literacy Network. Retrieved February 2, 2020 from https://creeliteracy.org/2017/11/10/typing-syllabics-on-your-computerinstalling-what-you-need-via-languagegeek/

RDA Toolkit. (n.d.). Retrieved February 3, 2020 from https://access.rdatoolkit.org/ Rigby, C. (2015). Nunavut Libraries Online Establish Inuit Language Bibliographic Cataloging Standards: Promoting Indigenous Language Using a Commercial ILS. Cataloging \& Classification Quarterly, 53(5/6), 615-639. https://doi.org/10.1080/01639374.2015.1008165

Robinson, O. (2019, September 3). Decolonizing the public library. Rabble.ca. Retrieved January 29, 2020 from https://rabble.ca/news/2019/09/decolonizingpublic-library 
Stevenson, W. (1999). Calling Badger and the Symbols of the Spirit Language: The Cree Origins of the Syllabic System. Oral History Forum, 19, 19-24. http://www.oralhistoryforum.ca/index.php/ohf/article/view/115

Truth and Reconciliation Commission of Canada. (2015). Truth and

Reconciliation Commission of Canada: Calls to Action. http://trc.ca/assets/pdf/Calls to Action English2.pdf

Vowel, Chelsea. (2011, December 11). Building relationships requires education. âpihtawikosisân. Retrieved February 3, 2020 from https://apihtawikosisan.com/2011/12/building-relationships-requires-education/ 